\title{
Expanding the Single-Visit Approach for Cervical Cancer Prevention: Successes and Lessons From Burkina Faso
}

\author{
Yacouba Ouedraogo, a Gahan Furlane, ${ }^{b}$ Timothee Fruhauf, ${ }^{c}$ Ousmane Badolo, ${ }^{a}$ Moumouni Bonkoungou, ${ }^{a}$ \\ Tsigue Pleah, ${ }^{\mathrm{b}}$ Jean Lankoande, ${ }^{\mathrm{d}}$ Isabelle Bicaba, ${ }^{\mathrm{e}}$ Eva S. Bazant ${ }^{\mathrm{b}}$
}

The single-visit approach was implemented with strong attention to systems in 14 health facilities. In the 2 largest facilities, nearly 14,000 women screened for cervical cancer over 4 years. Of approximately $9 \%$ who screened positive, about $66 \%$ received same-day cryotherapy. Attention is needed to ensure local technicians can repair cryotherapy equipment, supplies are consistently in stock, and user fees are not prohibitive to accessing care.

Résumé en français à la fin de l'article.

\section{ABSTRACT}

Background: Cervical cancer accounts for $23 \%$ of cancer incidence and $22 \%$ of cancer mortality among women in Burkina Faso. These proportions are more than 2 and 5 times higher than those of developed countries, respectively. Before 2010, cervical cancer prevention (CECAP) services in Burkina Faso were limited to temporary screening campaigns.

Program Description: Between September 2010 and August 2014, program implementers collaborated with the Ministry of Health and professional associations to implement a CECAP program focused on coupling visual inspection with acetic acid (VIA) for screening with same-day cryotherapy treatment for eligible women in 14 facilities. Women with larger lesions or lesions suspect for cancer were referred for loop electrosurgical excision procedure (LEEP). The program trained providers, raised awareness through demand generation activities, and strengthened monitoring capacity.

Methods: Data on program activities, service provision, and programmatic lessons were analyzed. Three data collection tools, an individual client form, a client registry, and a monthly summary sheet, were used to track 3 key CECAP service indicators: number of women screened using VIA, proportion of women who screened VIA positive, and proportion of women screening VIA positive who received same-day cryotherapy.

Results: Over 4 years, the program screened 13,999 women for cervical cancer using VIA; 8.9\% screened positive; and 65.9\% received cryotherapy in a single visit. The proportion receiving cryotherapy on the same day started at a high of $82 \%$ to $93 \%$ when services were provided free of charge, but dropped to $51 \%$ when a user fee of $\$ 10$ was applied to cover the cost of supplies. After reducing the fee to $\$ 4$ in November 2012, the proportion increased again to 78\%. Implementation challenges included difficulties tracking referred patients, stock-outs of key supplies, difficulties with machine maintenance, and prohibitive user fees. Providers were trained to independently monitor services, identify gaps, and take corrective actions.

Conclusions: Following dissemination of the results that demonstrated the acceptability and feasibility of the CECAP program, the Burkina Faso Ministry of Health included CECAP services in its minimum service delivery package in 2016. Essential components for such programs include provider training on VIA, cryotherapy, and LEEP; provider and patient demand generation; local equipment maintenance; consistent supply stocks; referral system for LEEP; non-prohibitive fees; and a monitoring data collection system.

\footnotetext{
a Jhpiego, Ouagadougou, Burkina Faso.

b Jhpiego, Baltimore, MD, USA.

‘Johns Hopkins University School of Medicine, Baltimore, MD, USA.

${ }^{\mathrm{d}}$ Société de Gynécologues et Obstétriciens du Burkina, Ouagadougou, Burkina Faso.

${ }^{\mathrm{e}}$ Ministère de la Santé du Burkina Faso, Ouagadougou, Burkina Faso.

Correspondence to Gahan Furlane (Gahan.Furlane@jhpiego.org).
}

\section{BACKGROUND}

lobally, cervical cancer has the third highest inciIdence rate of all cancers in women, with more than 500,000 new cases per year, and causes an estimated 265,672 deaths per year. ${ }^{1}$ In Burkina Faso, the cervical cancer incidence and related mortality exceeds that of any other cancer in women, ${ }^{1}$ accounting for $23 \%$ of cancer incidence and $22 \%$ of cancer mortality. While these proportions are comparable with 
those of sub-Saharan Africa generally (25\% incidence and 23\% mortality) and Western Africa specifically $(24 \%$ and $22 \%$, respectively), they represent more than 2 times the incidence rate and 5 times the mortality rate of developed countries. ${ }^{1}$

In many developing countries, few skilled professionals are trained for cytology-based cervical cancer screening and surgical treatment of lesions, and the resources to sustain these costly services are also absent. ${ }^{2}$ Highly sensitive diagnostic and treatment tools including human papilloma virus testing and thermal coagulation require advanced health infrastructure and remain costly and vulnerable to loss of patients to follow-up. ${ }^{3-5}$ Visual inspection with diluted acetic acid (VIA) coupled with cryotherapy treatment for precancerous lesions is recommended by the World Health Organization (WHO) ${ }^{6}$ as an alternative, low-cost screening and treatment method. This single-visit approach (SVA) requires minimal infrastructure and can be practiced by nonphysician health care providers following targeted training. $^{2,7,8}$ In Burkina Faso, the Ministry of Health $(\mathrm{MOH})$, professional associations, and various organizations have organized cervical cancer screening campaigns using VIA since the mid2000s. However, treatment for precancerous lesions, including cryotherapy, had remained unavailable, leaving Burkina Faso's 1.7 million women ages 30-59 years without access to secondary prevention of cervical cancer. 9,10

SVA has been implemented in several lowresource settings and its documented effectiveness has the potential to reduce cervical cancer mortality. ${ }^{1,12}$ Scale-up efforts are now underway in a number of countries, bridging screening and treatment services for cervical cancer prevention (CECAP). ${ }^{12-14}$ SVA is feasible, well-accepted, and safe despite initial concerns. ${ }^{2,15,16}$ However, debate remains regarding the best implementation approach for training providers, ${ }^{2,14,17}$ retaining providers, ${ }^{14,18-20}$ minimizing attrition through task shifting, ${ }^{12,21}$ and ensuring sustainability and integration of CECAP services into the health system. ${ }^{2,7,12,20-22}$ The wide spectrum of experiences in introducing SVA in several locations underlines the importance of adapting the implementation approach to the local context. In the interest of South-South collaboration, all experiences implementing SVA need to be widely shared so that programs can benefit from practical learning and CECAP services can be offered at scale..$^{2,7,23}$

We describe the implementation of an integrated CECAP program in 14 health facilities, the challenges encountered, how they were overcome, and the outcomes of the program in the 2 teaching hospitals. Lessons for implementation and advocacy are drawn with the aim of benefiting other countries similarly expanding CECAP services.

\section{PROGRAM DESCRIPTION}

Between September 2010 and August 2014, the project aimed to expand CECAP services in 14 health facilities at different levels in the health system throughout Burkina Faso by introducing VIA screening coupled with cryotherapy for precancerous lesions in a single visit. A second aim was to develop program monitoring skills among providers to foster independent and local improvement in service provision. The project's activities, described in the Table, encompassed training health care providers, demand generation, and capacity building in monitoring and evaluation.

The CECAP program was started in 5 facilities as a collaborative project between the $\mathrm{MOH}$ and the implementing organization, Jhpiego, an American nonprofit organization focused on improving health systems and operating in more than 30 low-income countries. Through a partnership between Jhpiego and the Burkinabe Society of Gynecology and Obstetrics (SOGOB), additional resources were later leveraged from the Society of Obstetricians and Gynecologists of Canada and SEMAFO, a Canadian-based mining company, to expand CECAP services to all 9 regional hospitals. In total, 14 facilities were included in the program: 2 teaching hospitals (or Centre Hospitalier Universitaire, CHU), all 9 regional hospitals, and 3 district hospitals.

The CECAP program provided individual counseling to women ages 25 to 59 . While cervical cancer screening programs typically start at age 30 , local gynecologists favored the inclusion of women as young as 25 years old in this intervention because median age at sexual initiation is 17.7 in Burkina Faso. ${ }^{24}$ The program used a standard clinical protocol for VIA and cryotherapy based on the WHO guidelines for screening and treatment of precancerous cervical lesions and adapted to Burkina Faso's context through expert consultation. ${ }^{25}$ Women who screened negative by VIA received counseling and instructions to schedule a follow-up appointment in 3 years, unless they were living with HIV in which case they scheduled a follow-up appointment for repeat screening in 1 year. Women who screened

\section{The single-visit approach to cervical cancer prevention requires minimal infrastructure and can be practiced by non-physician health care providers.}

\author{
The single-visit \\ approach was \\ implemented in \\ 14 health facilities \\ in Burkina Faso \\ between 2010 and \\ 2014.
}


TABLE. Objectives and Components of the CECAP Program in Burkina Faso

\begin{tabular}{|c|c|c|c|c|}
\hline Objectives & Intervention & Activities & Challenges & Solutions \\
\hline $\begin{array}{l}\text { To strengthen institutional } \\
\text { and provider capacity to } \\
\text { provide CECAP services }\end{array}$ & Training & $\begin{array}{l}\text { - Provision of initial equipment } \\
\text { for VIA, cryotherapy, and } \\
\text { LEEP including parts and } \\
\text { supplies } \\
\text { - Training of providers in } \\
\text { counseling, VIA, cryotherapy, } \\
\text { and LEEP } \\
\text { - Supportive supervision visits to } \\
\text { mentor and support providers }\end{array}$ & $\begin{array}{l}\text { - Cryotherapy machine } \\
\text { maintenance was } \\
\text { performed abroad, } \\
\text { reducing availability of } \\
\text { services } \\
\text { - Shortage of supplies for } \\
\text { VIA and cryotherapy } \\
\text { (acetic acid, carbon } \\
\text { dioxide, swabs, gauze) }\end{array}$ & $\begin{array}{l}\text { Training local technicians } \\
\text { to perform maintenance of } \\
\text { cryotherapy machines } \\
\text { internally } \\
\text { - Charging user fees to } \\
\text { finance some of the costs of } \\
\text { the procedures }\end{array}$ \\
\hline $\begin{array}{l}\text { To increase awareness about } \\
\text { cervical cancer and CECAP } \\
\text { services among providers } \\
\text { and patients }\end{array}$ & Demand generation & $\begin{array}{l}\text { Group education in facilities } \\
\text { about cervical cancer and } \\
\text { CECAP services } \\
\text { - Television programs about } \\
\text { cervical cancer and CECAP } \\
\text { services }\end{array}$ & $\begin{array}{l}\text { Prohibitive user fees } \\
\text { deterred demand for } \\
\text { cryotherapy services at the } \\
\text { same visit as screening }\end{array}$ & $\begin{array}{l}\text { The implementing } \\
\text { organization and SOGOB } \\
\text { used a costing analysis to } \\
\text { advocate for a reduced } \\
\text { user fee in line with } \\
\text { patients' financial capacity }\end{array}$ \\
\hline
\end{tabular}

Abbreviations: CECAP, cervical cancer prevention; LEEP, loop electrosurgical excision procedures; SOGOB, Burkinabe Society of Gynecology and Obstetrics; VIA, visual inspection with acetic acid.

positive by VIA and were eligible for cryotherapy received it at the time of the screening upon consenting to the procedure.

Eligibility for cryotherapy was based on WHO guidelines ${ }^{6}$ :

1. The lesion is not suspicious of cancer.

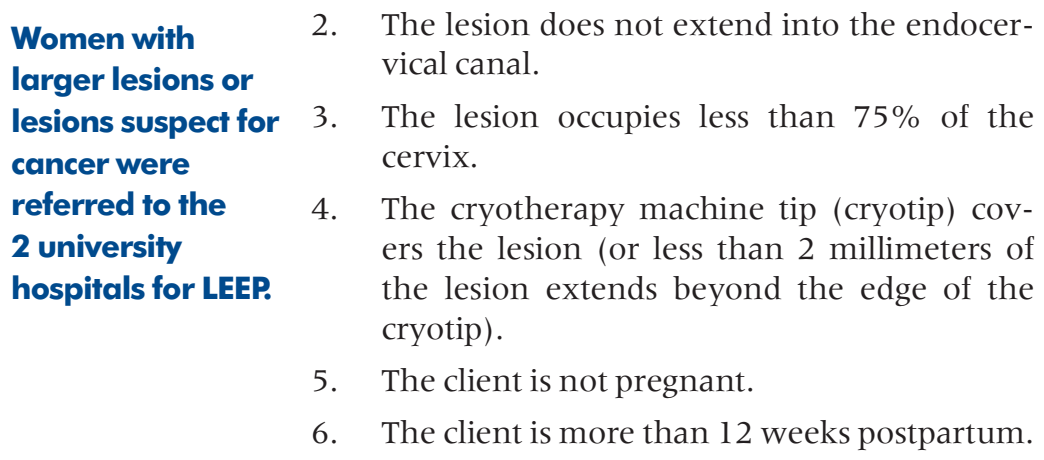

Women found to have larger lesions or lesions suspect for cancer were referred to the 2 university hospitals for loop electrosurgical excision procedure (LEEP) as part of the program's comprehensive secondary prevention services.

\section{Training}

We first trained 10 providers on VIA and cryotherapy in Malawi and Côte d'Ivoire during a 6-day training that gathered national training experts. Sessions were adapted to focus on the trainees' weaknesses identified through an initial assessment of baseline knowledge and skills. Training covered the general gynecologic exam, recognition of cervical landmarks and lesions, and interpretation of VIA results using photographic images. It also included practical training on 
conducting VIA and cryotherapy using anatomical models. These trained trainers then received technical assistance from Jhpiego to introduce SVA in their respective hospitals and train additional providers using the same 6-day training curriculum. The new trainers trained an additional 21 gynecologists, 2 general practitioners, and 27 nurse-midwives. Newly trained providers worked in pairs with a seasoned gynecologist or nurse-midwife who supervised their practice of VIA and cryotherapy for a minimum of 1 month. Eleven gynecologists were also trained to perform LEEP through a dedicated training organized by experts from Jhpiego.

\section{Demand Generation}

Demand for cervical cancer prevention services was generated through organized educational activities. Every morning, trained midwives would facilitate informal educational discussions in the waiting areas for family planning and antenatal care services. Topics covered the female genital tract, the presentation of cervical cancer, cervical cancer screening, and available services. Service providers at the same facilities that were not trained in CECAP were also targeted with messages about the benefits of cancer screening and the introduction of SVA. In addition, trained providers received supportive supervision visits reinforcing SVA and CECAP service delivery standards, and a dedicated team of gynecologists and data managers ensured the quality of services through quarterly monitoring visits that followed Jhpiego's CECAP Monitoring and Evaluation Strengthening Guidelines. As part of the quality verification system, the gynecologists and data managers monitored inter-provider variation and reviewed pathology for some patients who underwent LEEP. Quality monitoring was particularly useful to identify providers over-diagnosing precancerous lesions and to define further training needs.

\section{Capacity Building in Monitoring and Evaluation}

Besides service provision and demand generation, the program also built local capacity for CECAP service monitoring. Providers at the 2 highestvolume sites, the CHUs, were engaged in collecting data and improving data quality to monitor service delivery outcomes. Midwives designated as data managers were trained to extract data, crosscheck values, and make corrections using tools developed by the program. Jhpiego and
SOGOB organized a quarterly review of service statistics and data quality checks: client forms, registries, and monthly summary sheets were crosschecked and discrepancies were discussed and corrected. Advice to improve data quality was shared with data managers. Providers were also trained to graph data on a laminated poster to display key indicators related to CECAP services. They used these charts to track the progress of program activities and disseminate results to program staff.

Program results were shared at national meetings that brought together program managers, SOGOB, other partners working in the realm of cervical cancer, and key decision makers including the $\mathrm{MOH}$ and the First Lady of Burkina Faso. Following these dissemination events, the government integrated CECAP into its national guidelines on cancer, Plan stratégique de la lute contre le cancer 2013-2017, ${ }^{26}$ thereby strengthening some of the program's achievements and sustainability.

\section{METHODS}

The program collected 3 types of data: (1) program reports describing activities undertaken to introduce SVA and monitor results, (2) service records describing the number of clients reached by the program, and (3) implementation lessons learned via discussions with key stakeholders.

First, program reports were used to collect results of CECAP activities in the 14 health facilities between September 2010 and August 2014. Program reports, written each quarter, described progress against program objectives.

Second, the program developed 3 tools for monitoring service data: an individual client form, a client registry in which each client was listed, and a monthly summary sheet. Individual client forms completed by providers at each visit included client identification information, HIV status, VIA results, relevant treatment information, and follow-up plans. Program data managers extracted data from individual forms to populate client registries. Facility staff aggregated the registry data on the monthly summary sheet. These tools collecting individual- and facility-level data were used to track progress of 3 indicators:

- The number of women screened using VIA.

- The proportion of women who screened VIA positive.

- The proportion of women screening VIA positive who received same-day cryotherapy in a single visit approach ("proportion SVA"). 


\section{Of those who screened positive, $66 \%$ received same-day treatment with cryotherapy.}

\section{Over 4 years, nearly 14,000 women were screened for cervical cancer and $9 \%$ screened positive.}

These indicators were disaggregated by HIV status according to Jhpiego's standard practice. HIV status was self-reported and extracted from the patient's medical booklet or assessed when the patient requested a voluntary HIV test. While this disaggregation was of interest for this program because of the increased risk for cervical cancer in women living with HIV, these numbers are not shown because Burkina Faso's HIV prevalence among women $15-49$ years is $1.2 \% .^{24}$ Program staff and clinical providers reviewed data compiled every quarter. The authors collected and reviewed monitoring data from the 2 larger health facilities. SOGOB collected and reviewed monitoring data from the other 12 facilities and those data are not shown.

Third, formative lessons about the implementation of CECAP services were drawn from program experiences through discussions among program staff and with key stakeholders at the dissemination and advocacy events in Burkina Faso.

This program does not constitute a research study. Data collection and monitoring activities were carried out for quality improvement purposes and therefore were not subject to approval by an institutional review board. Privacy and confidentiality of personal information was maintained throughout data collection and analysis. All data kept by the program were de-identified.

\section{RESULTS}

\section{Trained Providers}

As mentioned previously, the program trained providers in VIA and cryotherapy through a partnership with programs in Malawi and Côte d'Ivoire. These trainers then trained 21 gynecologists, 2 general practitioners, and 21 nurse-midwives in Burkina Faso. In addition, 11 providers in the 2 CHUs were trained to provide LEEP for cases ineligible for cryotherapy. All providers continued to provide CECAP services over the course of the 4 years; no attrition was recorded. All SVA-trained providers were inclu-ded in program monitoring workshops conducted throughout the 4-year implementation period; supportive supervision visits decreased in frequency over that time. Demand generation activities were conducted in all 14 facilities.

\section{Screened Clients}

Over the course of 4 years, 13,999 women were screened for cervical cancer using VIA. On average, $8.9 \%$ of the women screened positive by VIA. Several trends can be noted. First, the number of screened women increased dramatically with demand generation efforts in the first full year (2011) and second year (2012), from 2,713 to 4,662 (Figure la). The end of the initial funding phase led to a decrease in the number of women screened in the second quarter of the third year because there were fewer supportive supervision visits and several facilities experienced stockouts of key supplies, including acetic acid, carbon dioxide, swabs, and gauze. Supportive supervision visits were less frequent but continued with assistance from SOGOB, the professional association.

Each quarter, 5\% to $17 \%$ of women screened VIA positive (dotted line in Figure la). This proportion was in line with the international standard benchmark of $5 \%$ to $10 \% .^{27}$ The percentage was higher at the beginning of the program because some health centers did not offer cryotherapy and referred VIA-positive clients to CHUs where women were retested. These repeated screening results were recorded as though they were first diagnoses. This tracking error was rectified in the second year: these clients were logged as referrals from other health centers rather than new clients.

\section{Treated Clients}

Of the 985 women who screened positive at first screening, 65.9\% (649) received same-day cryotherapy treatment (Figure 1b). Additionally, 200 women received LEEP on a later date and 176 of these occurred in the 2 CHUs. Moreover, 151 women were referred for surgical management of suspected cancer. The proportion of VIA positive women who were treated with cryotherapy varied between $38 \%$ and $100 \%$ by quarter. This proportion was high (82\% to $93 \%)$ at the start of the program when sites offered free cryotherapy because carbon dioxide gas was provided free of charge for the procedure. Later, when facilities were expected to support these costs, the SVA rate declined to $51 \%$ when a user fee for VIA and cryotherapy was charged to cover the cost of supplies. The prohibitively expensive fees (approximately $\$ 10$ in a country where $44.5 \%$ of the population was living on less than $\$ 1.25$ per day in $2009^{28}$ ) led many women to postpone cryotherapy.

The increase in the proportion of VIA positive women treated with cryotherapy in late 2012 may have been linked to two changes. First, program implementers and SOGOB advocated for lower prices to the $\mathrm{MOH}$ and facilities management teams. In November 2012, after the cryotherapy fee was reduced to $\$ 4$ in CHUs, the proportion of women receiving cryotherapy increased again to $78 \%$. 
FIGURE 1. Trends in Cervical Cancer Screening, VIA Positivity, and Treatment, 2 Teaching Hospitals in Burkina Faso, September 2010-August 2014

a. Trend in VIA positivity over Program Duration for Newly Screened Women

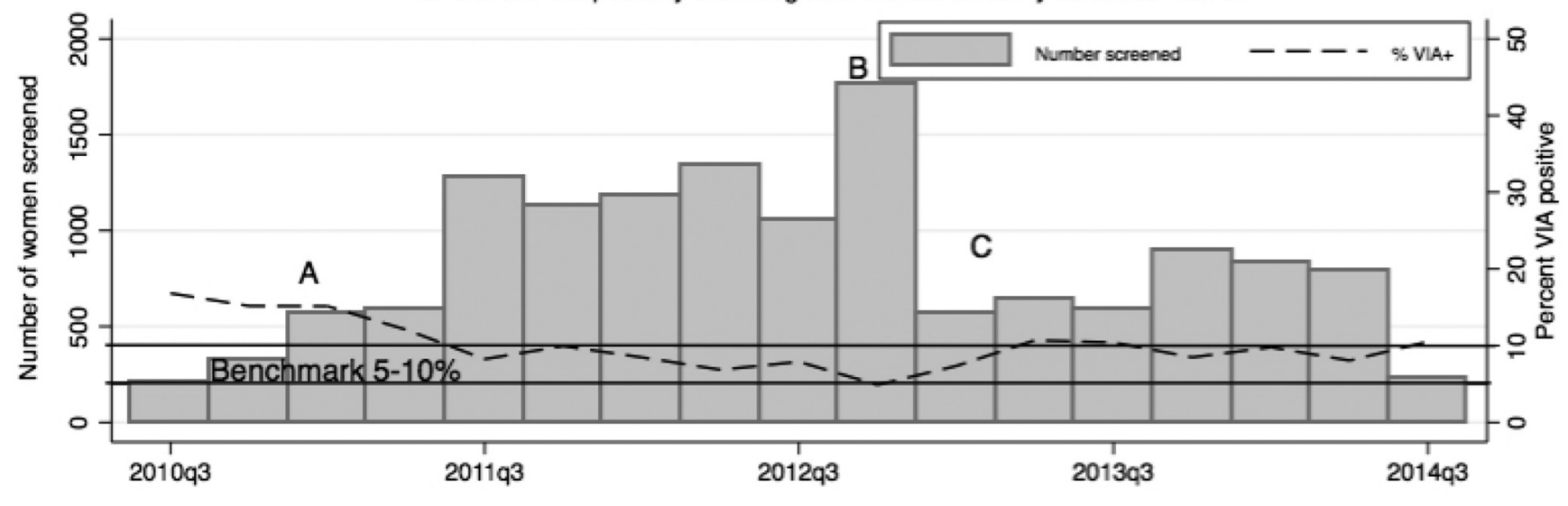

b. Single Visit Approach Treatment Received over Program Duration

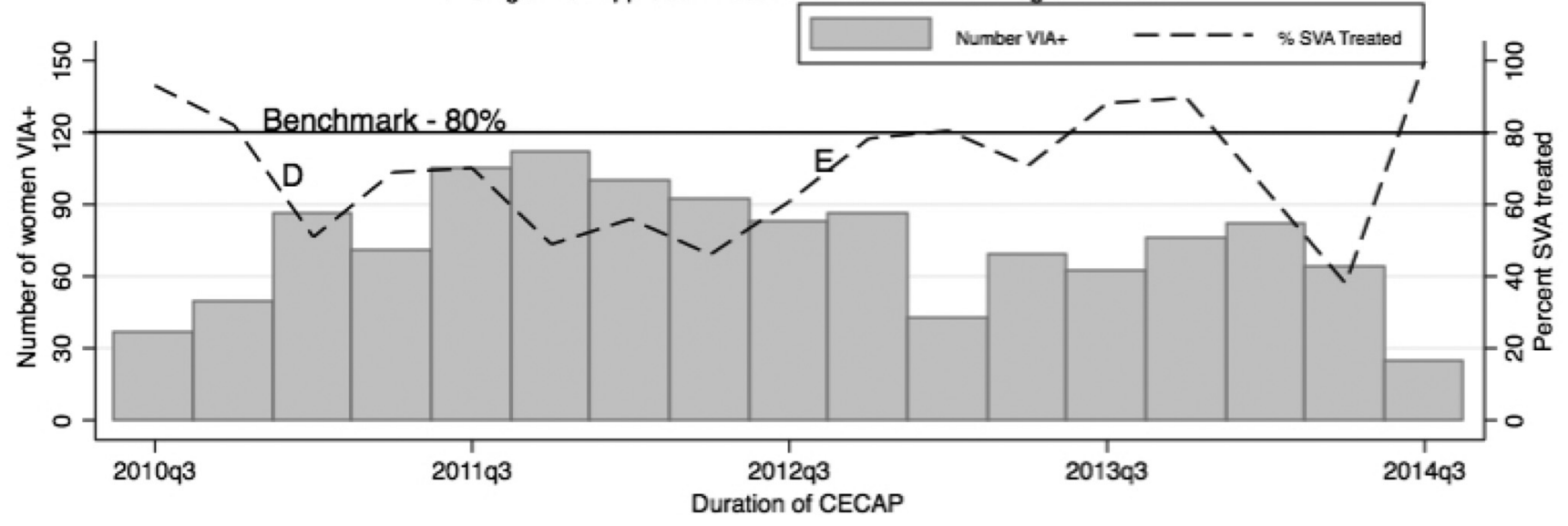

Abbreviations: CECAP, cervical cancer prevention; SVA, single-visit approach; VIA, visual inspection with acetic acid.

Notes:

A. February 2011 : Revision to the data collection tools to differentiate between clients referred for cryotherapy from other centers and clients making initial visits.

B. October 201 3: Television broadcast on cervical cancer by University Hospital Sorou Sanon.

C. January-June 2013: Period without financial resources for supervision and procurement of consumables.

D. January 2011 : Facilities begin requiring payment for VIA and cryotherapy.

E. November 2012: Cost reduction for cryotherapy.

Second, the capacity to repair cryotherapy machines improved locally. Treatment services had typically been intermittently halted when broken cryotherapy machines were sent out of the country for repairs. In 2012, the program hired the cryotherapy machine manufacturer to train 12 onsite technicians from the health facilities to repair machines. Maintenance and repairs were then conducted onsite reducing hiatuses in treatment provision.

\section{Midcourse Corrections Based on Use of Program Monitoring Data}

Providers collected data on services through the 3 tools-client forms, the client registry and monthly summary sheets-allowing the onsite managers and providers themselves to visualize progress, analyze trends, and identify potential bottlenecks in service provision. Displaying key indicators on posters meant providers had the 
tools to evaluate themselves and take corrective actions in real time. For instance, providers noticed that the proportion of women who screened positive by VIA was higher than expected and identified the source to be the incorrect recording of referred patients. Women with positive VIA tests at outside facilities who were referred for cryotherapy had a repeat VIA test prior to cryotherapy leading referred patients to be counted twice as having positive VIA tests. By tracking indicators, they also realized that the fees charged to patients were too high and gathered evidence to effectively convince facility managers to reduce these costs.

\section{DISCUSSION}

The program introduced comprehensive CECAP services through same-day VIA screening and cryotherapy treatment for eligible women in 14 health facilities in Burkina Faso through the combined efforts of several institutions. The program had several components: (1) training providers to engage in same-day screening using VIA and cryotherapy for treatment, and referral for and performance of LEEP for women with larger lesions or lesions suspect for cancer, (2) generating demand for cervical cancer prevention services among patients and

Once the program started charging treatment fees, the proportion of patients treated in a single visit dropped, from over $80 \%$ to $51 \%$. When the fees were lowered, this proportion increased to $78 \%$.

The MOH
integrated
cervical cancer
prevention
services into its
strategic planning
document, laying
the way forward
for possible future
expansion in the
country.
providers, and (3) building capacity among providers to collect and use monitoring data to track progress and take corrective actions locally. Over 4 years, this approach allowed the program to screen 13,999 women for cervical cancer, detect $8.9 \%$ of VIA-positivity among women screened, and treat $65.9 \%$ of the women testing VIApositive in a single visit. The $80 \%$ treatment target set by the program was reached at the start of the program when services were provided free of charge, but once the program started charging treatment fees to cover the cost of supplies, the proportion treated in a single visit dropped to $51 \%$ because the user fees were prohibitive. Once the fees were lowered from $\$ 10$ to $\$ 4$, the proportion treated in a single visit increased again to $78 \%$.

Overall, the program increased awareness of cervical cancer prevention services among patients, leading to service uptake from previous levels of zero (as services were not offered before this program). Program uptake suggests the acceptability and feasibility of such a program in Burkina Faso in the context of donor funding. Following the dissemination of the program's results, the $\mathrm{MOH}$ integrated CECAP services into its strategic planning document, laying the way forward for possible future expansion of comprehensive CECAP services in Burkina Faso. Since then, all health districts have included CECAP services in their annual action plans, especially with regard to provider training. The $\mathrm{MOH}$ is developing strategies to overcome gaps in availability of cryotherapy equipment.

Challenges related to implementation occurred. First, referred women who received a repeat screening were initially counted twice when tracking the provision of services; this was later corrected by including referral status in the registries. Second, some facilities could not provide CECAP services continuously because there were shortages of supplies necessary for VIA and cryotherapy. In addition, sometimes cryotherapy machines were unavailable when they were being repaired in other countries. Training local technicians to perform maintenance internally in the facilities and charging fees to finance some of the costs of the procedure addressed some of these issues. Third, fees were initially set at a prohibitive level for the patient population and deterred use of the services. SOGOB negotiated a lowering of these fees to an appropriate level.

This program experience confirms many aspects of SVA implementation detailed in the literature. For example, data monitoring and quality checks have been beneficial to CECAP service provision in published experiences. ${ }^{12,20,21,29-31}$ However, only this Burkina Faso program has integrated that aspect in a framework of capacity building and placed local providers at the center of using that data for problem and solution identification. Other programs also noted the importance of continued supervision to guarantee quality outcomes $^{8,12,32}$ and access to consistent supplies and operational equipment. 5,12,30,33 The literature also reports on the difficulty of maintaining the screen-and-treat continuum by minimizing loss to follow-up and ensuring that women return for cryotherapy if the SVA is not possible for a patient. ${ }^{14,22,33}$ This program identified user cost as a key barrier to follow-up and successfully addressed it. Finally, support from the $\mathrm{MOH}$ was also found to be instrumental in incorporating CECAP services into the health agenda and scaling up services in Botswana, Guyana, Mozambique, Tanzania, and Zambia. ${ }^{20,21,32,34-36}$

\section{Essential Components and Lessons Learned}

In light of these challenges faced by the Burkina Faso program and those recounted in the literature, essential components for the establishment of a national CECAP program include: 
1. Adequate training of physicians and midlevel providers, including nurses and nurse-midwives, accompanied by a quality assurance protocol.

2. Effective demand generation campaigns targeting patients and providers.

3. Local cryotherapy equipment maintenance.

4. Consistent stocks of VIA and cryotherapy supplies.

5. A referral system for large lesions that need LEEP and suspect cancer cases.

6. Non-prohibitive fees that allow access to services.

7. A robust routine monitoring data collection system used to identify and address service delivery gaps.

Some components are likely setting-specific and should be adapted to consider local contexts.

Three key lessons can be drawn from the implementation of this CECAP program. First, fostering champions of cervical cancer prevention was essential to influence stakeholders and decision makers to increase their commitment to CECAP services. This program nurtured these reproductive health champions and trained them to adopt and promote SVA for cervical cancer. They trained additional providers, which expanded the reach of the program. Their leadership led to increased interest in CECAP services not only among other medical professionals, including obstetricians-gynecologists, nurses and midwives, and SOGOB generally, but also among political figures and experts at the $\mathrm{MOH}$.

Second, the collection, visualization, and display of routine monitoring data in real time by the providers themselves empowered them to track progress, identify gaps, and take corrective actions to remedy any shortcomings, thereby reaching more successful outcomes. The program's focus on strengthening the monitoring capacity of local providers enabled them to become participants in the program's success and essential players in not only identifying issues themselves but also conceptualizing innovative solutions. For instance, through these monitoring data, providers were actively engaged in brainstorming solutions about tracking women referred to other facilities to report accurate indicators, reducing the cost of cryotherapy for patients, and improving internal machine maintenance capacity.
Third, stakeholder coordination under the umbrella of national guidelines is essential to ensure the growth and sustainability of a cervical cancer prevention program focused on increasing the provision of services. Prior to 2013, there was no national program dedicated to CECAP and different stakeholders lacked coordination: local associations conducted separate outreach campaigns for cervical cancer screening without linking screening to timely and appropriate treatment in a facility. Providers did not have the technical support they needed to introduce comprehensive CECAP services. Supportive supervision from district management teams to health facilities did not include CECAP, and the health management information system did not collect data on CECAP. Through training of trainers, technical assistance, and capacity building on monitoring, this program began to coordinate the different players with a role in the provision of CECAP services among the 14 facilities where it was implemented.

Gathering key decision makers for the dissemination of the program's results and engaging them in the successes, shortcomings, and revisions of the experience illustrated not only the importance of cervical cancer prevention services in Burkina Faso but also the acceptability, feasibility, and impact of providing these services. This process is believed to be essential to the sustainability of providing CECAP services. Since the program's end, CECAP services have continued to be offered routinely in the 14 sites and supplies and materials for these activities have been included in the facilities' budgets.

These dissemination efforts were also crucial for sustainability at the national level. Advocacy activities conducted with SOGOB lent support to CECAP services and promoted the integration of VIA-based screening and cryotherapy in the national plan for cancer control. In March 2016, the MOH issued a decree making cervical and breast cancer screening and basic treatment free of charge. In April 2016, CECAP became part of the minimum package of services offered to women in facilities in Burkina Faso. Through these commitments, Burkina Faso has progressively become a model for the successful integration of cervical cancer prevention efforts in resource-limited settings and illustrated a path toward implementing a part of the global cancerfree agenda.

Acknowledgments: The authors thank the Ministry of Health of Burkina Faso (including Amedee Prosper Dijguemde, Dieneba Sanon, and Gnangao Carine) and the Societé de Gynécologues et Obstétriciens du 
Burkina (including Blandine Thieba, Michel Akotionga, and Linda Traore) for its support and partnership in implementation. The authors also thank support staff in Burkina Faso and Baltimore during the program period: Stanislas Nebie, Mathurin Dodo, Cheick Ouedraogo, Rachel Waxman, Danielle Burke, and Megan Wysong. The authors acknowledge Diwakar Mohan for assistance with data analysis and visualization and to Supriya Mehta and Edward Kenyi for their review of the manuscript.

Funding: Izumi Foundation

Competing Interests: Dr. Lankoande reports grants from The Society of Obstetricians and Gynecologists of Canada during the conduct of the study. Ms. Furlane, Mr. Ouedraogo, Dr. Badolo, Mr. Bonkoungou, Dr. Bazant, and Dr. Pleah report grants to Jhpiego from Izumi Foundation during the conduct of the study. Jhpiego general funds supported the development of this manuscript after the grant period ended.

\section{REFERENCES}

1. World Health Organization International, Agency for Research on Cancer. Population fact sheets. GLOBOCAN 2012: Estimated Cancer Incidence, Moratlity and Prevalence Worldwide in 2012 website. http://globocan.iarc.fr/Pages/fact_sheets population. aspx. Accessed March 7, 2017

2. Blumenthal PD, Gaffikin L, Deganus $S$, Lewis R, Emerson $M$ Adadevoh S; Ghana Cervicare Group. Cervical cancer prevention: safety, acceptability, and feasibility of a single-visit approach in Accra, Ghana. Am J Obstet Gynecol. 2007;196(4):407.el-e8; discussion 407.e8-e9. CrossRef. Medline

3. Mustafa RA, Santesso N, Khatib R, et al. Systematic reviews and meta-analyses of the accuracy of HPV tests, visual inspection with acetic acid, cytology, and colposcopy. Int $J$ Gynaecol Obstet. 2016;132(3):259-265. CrossRef. Medline

4. Hoppenot C, Stampler K, Dunton C. Cervical cancer screening in high-and low-resource countries: implications and new developments. Obstet Gynecol Surv. 2012;67(10):658-667. CrossRef. Medline

5. Sankaranarayanan R, Anorlu R, Sangwa-Lugoma G, Denny LA. Infrastructure requirements for human papillomavirus vaccination and cervical cancer screening in sub-Saharan Africa. Vaccine. 2013;31 (suppl 5):F47-F52. CrossRef. Medline

6. World Health Organization (WHO). Guidelines for Screening and Treatment of Precancerous Lesions for Cervical Cancer Prevention: WHO Guidelines. Geneva: WHO; 2013. http://www.who.int/ reproductivehealth/publications/cancers/screening_and treatment_of_precancerous_lesions/en. Accessed March 27, 2018

7. Vet JNI, Kooijman JL, Henderson FC, et al. Single-visit approach of cervical cancer screening: see and treat in Indonesia. $\mathrm{Br} J$ Cancer. 2012;107(5):772-777. CrossRef. Medline

8. Blumenthal PD, Lauterbach M, Sellors JW, Sankaranarayanan R. Training for cervical cancer prevention programs in low-resource settings: Focus on visual inspection with acetic acid and cryotherapy Int J Gynaecol Obstet. 2005;89(suppl 2):S30-S37. CrossRef. Medline

9. Compaore S, Ouedraogo CMR, Koanda S, Haynatzki G, Chamberlain RM, Soliman AS. Barriers to cervical cancer screening in Burkina Faso: needs for patient and professional education. J Cancer Educ. 2016;31(4):760-766. CrossRef. Medline

10. Ministère de l'Economie et des Finances, Secrétariat Général, Institut National de la Statistique et de la Démographie du Burkina Faso. Recensement Général de la Population et de l'Habitation (RGPH) de 2006: Analyse des Résultats Définitifs. Ouagadougou, Burkina Faso: Ministère de l'Economie et des Finances; 2009. http:// www.insd. $\mathrm{bf} / \mathrm{n} /$ contenu/enquetes_recensements/rgph-bf/themes_en_ demographie/Theme2-Etat_et_structure_de_la_population.pdf. Accessed March 27, 2018.
11. Chumworathayi B, Srisupundit S, Lumbiganon P, Limpaphayom KK. One-year follow-up of single-visit approach to cervical cancer prevention based on visual inspection with acetic acid wash and immediate cryotherapy in rural Thailand. Int $J$ Gynecol Cancer. 2008;18(4):736-742. CrossRef. Medline

12. Martin CE, Tergas Al, Wysong M, Reinsel M, Estep D, Varallo J. Evaluation of a single-visit approach to cervical cancer screening and treatment in Guyana: feasibility, effectiveness and lessons learned. J Obstet Gynaecol Res. 2014;40(6):1707-1716. CrossRef. Medline

13. Finocchario-Kessler S, Wexler C, Maloba M, Mabachi N, Ndikum-Moffor F, Bukusi E. Cervical cancer prevention and treatment research in Africa: a systematic review from a public health perspective. BMC Women's Health. 2016;16(1):29. CrossRef. Medline

14. Chary AN, Rohloff PJ. Major challenges to scale up of visual inspection-based cervical cancer prevention programs: the experience of Guatemalan NGOs. Glob Health Sci Pract. 2014; 2(3):307-317. CrossRef. Medline

15. Gaffikin L, Blumenthal PD, Emerson M, Limpaphayom K; Royal Thai College of Obstetricians and Gynaecologists (RTCOG)/JHPIEGO Corporation Cervical Cancer Prevention Group [corrected]. Safety, acceptability, and feasibility of a single-visit approach to cervicalcancer prevention in rural Thailand: a demonstration project. Lancet. 2003;361(9360):814-820. CrossRef. Medline

16. Fallala MS, Mash R. Cervical cancer screening: safety, acceptability, and feasibility of a single-visit approach in Bulawayo, Zimbabwe. Afr J Prim Heal Care Fam Med. 2015;7(1). CrossRef. Medline

17. Vedantham H, Silver MI, Kalpana B, et al; CATCH Study Team. Determinants of VIA (Visual Inspection of the Cervix After Acetic Acid Application) positivity in cervical cancer screening of women in a peri-urban area in Andhra Pradesh, India. Cancer Epidemiol Biomarkers Prev. 2010;19(5):1373-1380. CrossRef. Medline

18. Luciani S, Winkler J. Cervical Cancer Prevention in Peru: Lessons Learned from the TATI Demonstration Project. Washington, DC: Pan American Health Organization; 2006. http://mww1 paho. org/english/ad/dpc/nc/pcc-cc-tati-rpt.pdf?ua=1. Accessed March 27, 2018.

19. Paul P, Winkler JL, Bartolini RM, et al. Screen-and-treat approach to cervical cancer prevention using visual inspection with acetic acid and cryotherapy: experiences, perceptions, and beliefs from demonstration projects in Peru, Uganda, and Vietnam. Oncologist. 2013;18(12):1278-1284. CrossRef. Medline

20. Maternal and Child Health Integrated Program (MCHIP). Guyana Cervical Cancer Prevention Project. Baltimore: Jhpiego; 2012. https://www.mchip.net/sites/default/files/MCHIP_Guyana\% 20Closeout\%20Report.pdf. Accessed March 27, 2018.

21. Parham GP, Mwanahamuntu MH, Kapambwe S, et al. Populationlevel scale-up of cervical cancer prevention services in a low-resource setting: development, implementation, and evaluation of the cervical cancer prevention program in Zambia. PLoS One. 2015;10(4): e0122169. CrossRef. Medline

22. Moon TD, Silva-Matos C, Cordoso A, Baptista AJ, Sidat M, Vermund $\mathrm{SH}$. Implementation of cervical cancer screening using visual inspecfion with acetic acid in rural Mozambique: successes and challenges using HIV care and treatment programme investments in Zambézia Province. J Int AIDS Soc. 2012;15(2):17406. CrossRef. Medline

23. Sauvaget C, Fayette JM, Muwonge R, Wesley R, Sankaranarayanan $R$. Accuracy of visual inspection with acetic acid for cervical cancer screening. Int J Gynaecol Obstet. 2011;113(1):14-24. CrossRef. Medline

24. Institut National de la Statistique et de la Démographie (INSD); ICF International. Enquête Démographique et de Santé et à Indicateurs Multiples du Burkina Faso 2010. Calverton, MD: INSD and ICF 
International; 2012. https://dhsprogram.com/pubs/pdf/FR256/ FR256.pdf. Accessed March 27, 2018

25. World Health Organization (WHO). Comprehensive Cervical Cancer Control: A Guide to Essential Practice. 2nd ed. Geneva: WHO; 2014. http://www.who.int/reproductivehealth/ publications/cancers/cervical-cancer-guide/en/. Accessed March 27, 2018

26. Ministère de la Santé du Burkina Faso. Plan Stratégique de Lutte Contre le Cancer 2013-2017. Ouagadougou, Burkina Faso: Ministère de la Santé du Burkina Faso; 2013. http:// www.iccpportal.org/system/files/plans/Burkina\%20Faso_Plan\%20strat\% C3\%A9gique\%20de\%20lutte\%20contre\%20le\%20cancer\% 202013-2017.pdf. Accessed January 3, 2018

27. World Health Organization (WHO); Pan American Health Organization. Monitoring National Cervical Cancer Prevention and Control Programmes: Quality Control and Quality Assurance for Visual Inspection with Acetic Acid (VIA)-Based Programmes. Geneva: WHO; 2013. http://apps.who.int/iris/bitstream/10665/ 79316/1/9789241505260_eng.pdf. Accessed March 27, 2018.

28. Population below $\$ 1.25$ (PPP) per day, percentage. UNdata [online database]. New York: United Nations Statistics Division. http://data.un.org/Data.aspx?d=MDG\&f=seriesRowID\%3A580. Accessed July 3, 2017.

29. Bradley J, Barone M, Mahé C, Lewis R, Luciani S. Delivering cervical cancer prevention services in low-resource settings. Int J Gynaecol Obstet. 2005;89(suppl 2):S21-S29. CrossRef. Medline
30. Kim YM, Lambe FM, Soetikno D, et al. Evaluation of a 5-year cervical cancer prevention project in Indonesia: opportunities, issues, and challenges. J Obstet Gynaecol Res. 2013;39(6):1 190-1199. CrossRef. Medline

31. Anderson J, Wysong M, Estep D, et al. Evaluation of cervical cancer screening programs in Côte d'Ivoire, Guyana, and Tanzania: effect of HIV status. PloS One. 2015;10(9):e0139242. CrossRef. Medline

32. Sanghvi $H$, Limpaphayom KK, Plotkin $M$, et al. Cervical cancer screening using visual inspection with acetic acid: operational experiences from Ghana and Thailand. Reprod Health Matters. 2008;16(32):67-77. CrossRef. Medline

33. Msyamboza KP, Phiri T, Sichali W, Kwenda W, Kachale F. Cervical cancer screening uptake and challenges in Malawi from 2011 to 2015: retrospective cohort study. BMC Public Health. 2016; 16(1):806. CrossRef. Medline

34. Samucidine M, Thuzine E, Vaz MDL, Reis V, Lu R. Implementing cervical cancer prevention programs at national scale in developing countries: Mozambique's successful experience. Int J Gynaecol Obstet. 2015;131(suppl 5):e270.

35. McCree R, Giattas MR, Sahasrabuddhe VV, et al. Expanding cervical cancer screening and treatment in Tanzania: stakeholders' perceptions of structural influences on scale-up. Oncologist. 2015;20(6):621-626. CrossRef. Medline

36. Grover S, Raesima M, Bvochora-Nsingo M, et al. Cervical cancer in Botswana: current state and future steps for screening and treatment programs. Front Oncol. 2015;5:239. CrossRef. Medline

\section{En français}

\section{Etendre l'approche de la visite unique pour la prévention du cancer du col de l'utérus : succès et leçons apprises du Burkina Faso}

L'approche de la visite unique a été mise en œuvre avec une attention particulière au renforcement du système dans 14 formations sanitaires. Dans les deux plus grandes structures sanitaires, près de 14000 femmes ont bénéficié d'un dépistage des lésions précancéreuses du col de l'utérus en quatre ans. Sur environ $9 \%$ de cas positifs, environ $66 \%$ ont reçu la cryothérapie le jour même. Une attention particulière est nécessaire pour s'assurer que les techniciens locaux peuvent réparer les équipements de cryothérapie, que les produits sont disponibles et que les tarifs pratiqués pour l'offre de service ne constituent pas une barrière a l'accès aux soins.

\section{RÉSUMÉ}

Contexte : Le cancer du col de l'utérus représente $23 \%$ de l'incidence du cancer et $22 \%$ de la mortalité par cancer chez les femmes au Burkina Faso. Ces proportions sont respectivement plus de 2 et 5 fois plus élevées que celles des pays développés. Avant 2010, les services de prévention du cancer du col de l'utérus (CECAP) au Burkina Faso se limitaient à des campagnes de dépistage sporadiques.

Description du programme : Entre septembre 2010 et aô̂t 2014, une équipe de Jhpiego a collaboré avec le ministère de la Santé et les associations professionnelles pour mettre en œuvre un programme CECAP axé sur le couplage de l'inspection visuelle du col a l'acide acétique pour le dépistage et le traitement par cryothérapie des lésions précancéreuses chez des femmes éligibles dans 14 formations sanitaires. Les femmes avec des lésions plus grandes ou des lésions suspectes de cancer ont été référées pour la résection a l'anse diathermique (RAD). Le programme a formé des prestataires, conduit des activités de sensibilisation pour la création de la demande et renforcé la capacité en suivi.

Méthodes : Les données sur les activités de programme, les prestations de services et les leçons programmatiques ont été analysées. Trois outils de collecte de données à savoir un formulaire individuel client, un registre client et une fiche de synthèse mensuelle ont été utilisés pour suivre trois principaux indicateurs de service CECAP : nombre de femmes dépistées à l'aide de l'IVA, proportion de femmes dépistées positives a l'IVA et proportion de femmes dépistées positives à l'IVA qui a reçu la cryothérapie le jour même du dépistage.

Résultats : En 4 ans, le programme a dépisté 13999 femmes pour les lésions précancéreuses du col de l'utérus en utilisant l'IVA; 8,9\% ont été dépistés positives; et 65,9\% d'entre elles ont reçu une cryothérapie au cours de la même visite. La proportion de patients recevant la cryothérapie le même jour est passée de $82 \%$ à $93 \%$ lorsque les services étaient fournis gratuitement, mais est tombée à $51 \%$ lorsque des tarifs d'environ $10 \$$ ont été appliqués pour couvrir le coût des prestations. Après avoir réduit les frais à environ $4 \$$ en novembre 2012, la proportion a encore augmenté pour atteindre $78 \%$. Les difficultés de mise en œuvre comprenaient celles du suivi des patients référés, les ruptures de stock de produits essentiels, les difficultés de maintenance des machines de cryothérapie et les tarifs prohibitifs appliqués pour les prestations de service. Les prestataires ont été formés pour assurer de manière autonome le suivi des indicateurs d'offre de services, identifier les lacunes et prendre des mesures correctives.

Conclusions : Après la diffusion des résultats démontrant l'acceptabilité et la faisabilité du programme CECAP, le ministère de la Santé du Burkina Faso a inclus les services CECAP dans son paquet de prestation de services minimum en 2016. Les composantes essentielles de ces types de programmes comprennent la formation des prestataires sur l'IVA, la cryothérapie et la résection a l'anse diathermique; la création de la demande des services au niveau des prestataires et des clients; la maintenance des équipements au niveau local; un approvisionnement adéquat en produits; un système de référence pour la RAD; des tarifs non prohibitifs et un système de collecte de données performant. 
Peer Reviewed

Received: August 17, 2017; Accepted: January 9, 2018

Cite this article as: Ouedraogo Y, Furlane G, Fruhauf T, Badolo $O$, Bonkoungou M, Pleah T, et al. Expanding the single-visit approach for cervical cancer prevention: successes and lessons from Burkina Faso. Glob Health Sci Pract. 2018;6(2):288-298. https://doi.org/10.9745/GHSP-D-1700326

(C) Ouedraogo et al. This is an open-access article distributed under the terms of the Creative Commons Attribution 4.0 International License (CC BY 4.0), which permits unrestricted use, distribution, and reproduction in any medium, provided the original author and source are properly cited. To view a copy of the license, visit http://creativecommons.org/licenses/by/4.0. When linking to this article, please use the following permanent link: https:// doi.org/10.9745/GHSP-D-17-00326 